SECCIÓN ESPECIAL

\title{
LA ELECCIÓN PRESIDENCIAL DE 2018
}

José Antonio Crespo*

RESUMEN: El presente texto elabora un análisis electoral y político de los comicios llevados a cabo en México en julio de 2018. Se muestran las diversas hipótesis que pueden explicar el triunfo de Andrés Manuel López Obrador. Un conjunto de factores políticos, sociales y hasta de carácter legal favorecieron la victoria electoral del Movimiento de Regeneración Nacional (Morena): el hartazgo político, la constante presencia de López Obrador, los conflictos entre el PRI y el PAN, la transferencia del voto útil y la actual estructura y normatividad legislativa que permiten mayorías artificiales.

গ্ৰ)

THE PRESIDENTIAL ELECTION OF 2018

ABSTRACT: This text prepares an electoral and political analysis of the elections held in Mexico in July 2018. It shows the different hypotheses that may explain the triumph of Andrés Manuel López Obrador. A set of political, social and even legal factors favored the electoral victory of the National Regeneration Movement (Morena): the political weariness, the constant presence of López Obrador, the conflicts between the PRI and the PAN, the transfer of the useful vote and the current structure and legislative regulations that allow artificial majorities.

PALABRAS CLAVE: Andrés Manuel López Obrador, legislativo, partidos políticos, política mexicana, voto útil.

KEY WORDS: Andrés Manuel López Obrador, congress, mexican politics, political parties, useful vote.

* Profesor afiliado, Centro de Investigación y Docencia Económicas. 
Se prohíbe su reproducción total o parcial por cualquier medio, incluido electrónico, sin permiso previo y por escrito de los editores.

RECEPCIÓN: 7 de noviembre de 2018.

APROBACIÓN: 21 de febrero de 2019.

DoI: $10.5347 / 01856383.0129 .000294418$

Estudios 129, pp. 127-151, vol. XVII, verano 2019. 


\section{LA ELECCIÓN PRESIDENCIAL DE 2018}

\section{Introducción}

$E_{n}$ el año 2000 se registró la primera alternancia pacífica en la presidencia de México. En la mayor parte de los países democráticos se alternan en el ejercicio del poder los grupos políticos, pero no en México. Los cambios en las leyes electorales hechos desde 1988, así como las tendencias a la baja de la votación del PRI, permitieron desde 1998 pronosticar que al fin se alternaría la presidencia. ${ }^{1}$ Las reformas de 1994 y, sobre todo, de 1996 implicaron que el gobierno mexicano ya no controlara la organización de las elecciones ni a la institución encargada, el Instituto Federal Electoral, por lo cual renunciaba implícitamente a la posibilidad de manipular los resultados a favor del partido oficial o de revertir un resultado adverso. En 1996 se cruzó finalmente el umbral de la competitividad, lo que implicaba que el PRI podría ser derrotado. La votación de ese partido, además, seguía su tendencia decreciente; obtuvo 39\% en 1997, así que se pensaba que en 2000 tendría probablemente una votación menor (en las nuevas elecciones presidenciales, el partido ganador obtenía menos porcentaje de la votación que en las elecciones intermedias anteriores). Con un probable 36 o $37 \%$ del voto, sería posible que el opositor más cercano atrajera

${ }^{1}$ Cfr. José Antonio Crespo, ¿Tiene futuro el PRI? Entre la disolución y la supervivencia, 1988, México, Grijalbo. 
una parte de voto útil del tercero en discordia y ganara. Así ocurrió, pues Vicente Fox, del PAN, obtuvo 43\% de los votos frente al 36\% de Francisco Labastida, del PRI.

La alternancia desembocó en una rápida decepción democrática, pues Fox no cumplió su compromiso esencial de modificar el régimen político, terminar con la impunidad y combatir la corrupción. Un nuevo candidato emergido de la izquierda (PRD), Andrés Manuel López Obrador se colocó como favorito. Sin embargo, por errores cometidos durante la campaña de 2006 perdió la ventaja y terminó en empate técnico con el candidato del PAN, Felipe Calderón, que ganó oficialmente con una diferencia de $0.56 \%$ del voto (unos 243000 votos). Hubo dudas y acusaciones de fraude por parte de López Obrador, pues, en efecto, cuando el margen de ventaja es tan cerrado, basta un número reducido de irregularidades o votos manipulados (que siempre ocurre en las elecciones mexicanas) para alterar el resultado. Lo que se pudo comprobar es que las discrepancias aritméticas en las actas superaron la diferencia entre los dos punteros, porque ni el IFE ni el TEPJF aceptaron abrir los paquetes electorales según los facultaba la ley. Así, de acuerdo con la propia ley, resulta imposible determinar con precisión, contundencia y certeza quién ganó. Pese a todo, el Tribunal Electoral dictaminó el triunfo de Calderón. Según encuestas, $50 \%$ de la ciudadanía consideró que no había habido fraude, 35\% sostenía que sí y 15\% que dijo que no sabía con certeza quién había ganado.

Quedó así la idea entre la izquierda (el PRD y posteriormente Morena, partido surgido de la fractura de aquel), que la democracia electoral solo funcionaba para los partidos de la "derecha", quienes sostenían el proyecto neoliberal instaurado en 1985, dejando al margen a la izquierda. Esta hipótesis fue repetida por esa misma izquierda en 2012, cuando ganó el candidato del PRI Enrique Peña Nieto, pero ahora con un margen de 7\% de la votación.

En realidad, podía afirmarse que cuando hubiera un triunfo holgado de esa izquierda, pese a las irregularidades e intentos de fraude por parte del PRI o del PAN, se tendría que reconocer el triunfo (como había ocurrido con el PAN en 2000). Esto ocurrió en 2018, y se confirmó la tesis de que la democracia electoral establecida desde 1988 permitiría el triunfo 
y reconocimiento de cualquier opción, siempre que la ventaja fuera clara. El candidato de Morena, López Obrador, por diferentes razones logró el triunfo con $53 \%$ de la votación y $30 \%$ de ventaja sobre su más cercano seguidor (Ricardo Anaya, del PAN). El resultado abrió una enorme válvula de escape a la tensión, enojo y hartazgo acumulados en los últimos sexenios por un desempeño insuficiente de los gobiernos del PAN y el PRI, además de actos escandalosos de corrupción que, en general, pasaron impunes. Es una de las ventajas de la democracia; cuando un gobierno o un proyecto de gobierno se han agotado, es posible cambiarlo y probar con otro por una vía pacífica y civilizada (al margen de los resultados que pueda arrojar esa nueva opción). De lo contrario, las tensiones y frustraciones acumuladas pueden estallar fuera de la vía institucional y provocar un episodio de inestabilidad política (como revoluciones, guerras civiles o golpes de Estado). Las razones del desenlace de 2018 son múltiples y, al menos las más relevantes, se explicarán en este ensayo.

\section{El hartazgo y la decepción democrática}

El hartazgo con el PAN y el PRI fue mayor en 2018 que en 2006 y en 2012, lo cual representó una gran ventaja para López Obrador, que era la opción natural para capitalizar ese descontento y enojo. De acuerdo con la encuestadora GEA-ISA, $82 \%$ consideraba que el rumbo era equivocado en materia política y $79 \%$ en materia económica. Además, $43 \%$ creía que la situación política era peor que el año anterior, $36 \%$ la consideraba peor en lo económico y $70 \%$ pensaba que el país atravesaba una crisis económica. ${ }^{2}$ Pese a la publicidad del PAN de representar un cambio, no ofreció ninguno sustancial en sus doce años de gobierno. Ese hartazgo, aunado a la amplia corrupción de políticos y gobernantes de todos los partidos, se tradujo en un revanchismo social y político de buena parte del electorado. También se buscaba dar oportunidad a una corriente política que hasta entonces no había gobernado el país. Como señaló Amparo Casar, "AMLO se ha apropiado de tres banderas poderosas: la bandera anticorrupción, la bandera antisistema y la bandera de que Morena nunca

${ }^{2}$ Encuesta GEA-ISA, junio, 2017. 
ha gobernado". ${ }^{3}$ Por su parte, Jorge Zepeda Patterson escribió: "Nadie tiene dudas de que tras doce años de gobierno panista y un repudiado regreso del PRI (los niveles de desaprobación del gobierno de Peña Nieto son históricos), ha llegado el momento de la izquierda. Casi hasta por razones pendulares, los votantes parecerían dispuestos a optar por lo que aún no han probado, a la luz de los problemas que vive el país". ${ }^{4}$ En 2018, el hartazgo era tal, que más electores estaban dispuestos a votar por la nueva opción, encarnada en Morena, que por los ya conocidos y que resultaron un fiasco, lo que hacía previsible un triunfo de López Obrador en su tercer intento. ${ }^{5}$ Más importante aún fue que los electores (unos más duros y otros más moderados) parecían dispuestos a pasar por alto cualquier error, exceso o dislate de su candidato, de modo que en las encuestas en 2017, que ubicaban a López Obrador como puntero, nunca registraron un descenso, ni siquiera en los momentos frágiles del candidato. Así, en una gira por Estados Unidos, López Obrador responsabilizó al Ejército (de manera cauta pero innegable) de la desaparición de los normalistas de Ayotzinapa, con lo que causó gran molestia en los mandos militares. Más tarde, en Chilpancingo, repitió sus acusaciones y ofreció una investigación verdadera en caso de llegar al poder. Muchos

132 desafectos compararon el desliz con el "síndrome Chachalaca" de 2006 (cuando López Obrador se enfrentó verbalmente a Fox, lo que le ganó críticas y deserciones), que inició un desplome de las intenciones de voto del candidato en ese año. Se esperaba que en las encuestas siguientes apareciera el candidato de Morena con menos ventaja (alrededor del 5\%). En una encuesta se indicó que López Obrador había descendido incluso al segundo lugar (por debajo de Margarita Zavala), debido a que "el líder de Morena, quien viajó a Estados Unidos en días pasados, pudo haber sufrido un raspón, luego de entrar en controversia con el padre de uno de los estudiantes de Ayotzinapa". ${ }^{6}$ Pero muchas otras encuestas

${ }^{3}$ Amparo Casar, "Austeridad no es igual a honestidad". Excélsior, 10 de mayo de 2017.

${ }^{4}$ Jorge Zepeda Patterson, “PRD ¿palero o salvaguarda de la izquierda?”, sin embargo, 11 de junio de 2017.

${ }^{5}$ Cfr. José Antonio Crespo, 2018: ¿Amlo presidente?, 2017, México, Grulla.

${ }^{6}$ El Financiero, 3 de abril de 2017. 
confirmaron su ventaja, de modo que el incidente no repercutió en su intención de voto. ${ }^{7}$ Tenía razón Sergio Sarmiento:

López Obrador [...] tiene la piel muy delgada cuando se le cuestiona a él, pero no se equivoca al señalar que las acusaciones no han afectado hasta ahora su popularidad [...] Muchos han sido los cuestionamientos a la honestidad de López Obrador [...] Nada de esto ha servido para reducir su popularidad entre sus simpatizantes. López Obrador goza del efecto teflón (todo se le resbala). ${ }^{8}$

El porcentaje de votos que las encuestas le atribuían reflejaba más un piso que un techo, pues no se reducía, cualquiera que fuera el comportamiento del candidato morenista, y en cambio quedaba abierto para crecer aún más (como ocurrió). Este marco general explica el triunfo final de López Obrador

\section{El que se mueve, sí sale}

Ser un personaje público puede ser una gran ventaja en una campaña electoral. Desde luego, no garantiza el triunfo; eso depende de la imagen que proyecte. Sin embargo, de los últimos comicios se desprende que es mejor lanzarse en búsqueda de la candidatura presidencial más temprano que esperar hasta el último momento. Esa variable no es determinante, pero ayuda y, por lo visto, no en poca medida. Al menos desde 2000 cambió la famosa regla de que "el que se mueve, no sale", según frase atribuida al legendario Fidel Velázquez, líder de la CTM del PRI. Los "tapados" no podían moverse más de la cuenta, pues eso mismo implicaría su descalificación de la sucesión presidencial. Pero una vez cruzado el umbral de la competitividad electoral en 1997, la regla cambió. Vicente Fox, siendo gobernador de Guanajuato, expresó tres años antes de las elecciones su deseo de ser el candidato de su partido. Se adelantó así a otros aspirantes dentro del PAN, quienes por diversas razones no

${ }^{7}$ El Universal, 4 de abril de 2007. Excélsior, 3 de abril de 2007.

8 "Ave del pantano". Reforma, 26 de abril de 2017. 
JOSÉ ANTONIO CRESPO

lograron reunir la fuerza suficiente para enfrentar al guanajuatense. Fox resultó ser candidato único de su partido. Además, en la contienda general su madruguete le resultó también ventajoso. También en 1997, Cuauhtémoc Cárdenas ganó la jefatura de gobierno del Distrito Federal, lo que le prestó una estupenda plataforma para la carrera presidencial de 2000. No hacía falta que aceptara abiertamente sus pretensiones, sino que se daban por sentadas. No obstante, cayó en una especie de inmovilismo que lo hizo perder su posición en las encuestas. Fox lo alcanzó y lo superó con claridad. Mientras tanto, los aspirantes del PRI mantenían un perfil bajo, como en los viejos tiempos, si bien llegado el momento (a fines de 1999) se realizaron elecciones internas con cuatro aspirantes. Paradójicamente, en esa ocasión el PRI fue el único de los grandes partidos que organizó una contienda interna, formalmente democrática (si bien la mayoría priista se alineó con el aspirante oficial, Francisco Labastida). Cuando Labastida asumió formalmente la candidatura, había obtenido cierta ventaja en las encuestas (por la atención que atrajo la insólita contienda interna), pero pronto empezó a rezagarse de Fox. Una explicación es que el panista llevaba años de campaña informal, en tanto que Labastida apenas la iniciaba.

En las elecciones de 2006 ocurrió algo semejante. El nuevo jefe de gobierno del Distrito Federal era López Obrador, y desde ese puesto inició su campaña a la presidencia, por más que dijera que "lo dieran por muerto". Así fue ocupando el primer lugar en las encuestas. Además, no tuvo un rival interno (Cárdenas quedó desplazado como líder moral y eventual candidato del PRD). Ya en 2005, López Obrador tenía cerca de 20 puntos porcentuales de ventaja. Por el lado del PAN, Fox, ya como presidente, pretendió reproducir las rígidas normas del antiguo priismo. El secretario de Energía, Felipe Calderón, no respetó los tiempos presidenciales y aceptó que en un acto público el gobernador panista de Jalisco lo proclamara candidato a la presidencia. Fox, en lugar de reprenderlo en privado, lo descalificó en público, lo que orilló a Calderón a renunciar al gabinete y continuar abiertamente su precampaña. En cambio, el favorito de Fox, el secretario de Gobernación Santiago Creel, respetó la regla de no moverse. Calderón ganó la contienda interna con amplitud. Así, 
haber actuado anticipadamente le resultó a Calderón más favorable que respetar la caduca regla priista de no moverse sino hasta el final.

Para 2012, Calderón no había aprendido de la experiencia de Fox ni de la suya propia, y decidió que los integrantes del gabinete (de donde surgiría su favorito) deberían acatar la regla disciplinaria. Mientras tanto, Josefina Vázquez Mota, fuera del gabinete y coordinadora de la diputación panista, empezó muy anticipadamente a hacer precampaña. Cuando al final de 2005 finalmente Calderón destapó a su favorito, el secretario de Hacienda Ernesto Cordero, Vázquez Mota ya había ganado mucho terreno y derrotó al aspirante calderonista. A cambio, Vázquez Mota fue abandonada por Calderón, quien no toleró que no se hubiera hecho a un lado para dar paso a Cordero. El PAN llegó dividido a las elecciones y cayó al tercer sitio. En este caso, haberse adelantado a los tiempos le permitió a Vázquez Mota ganar la candidatura de su partido.

En estas mismas elecciones, el priista Peña Nieto también se movió con mucha antelación dentro de su partido. Desde que llegó a la privilegiada gubernatura del Estado de México en 2005, movió sus fichas para alinearse a las cúpulas y gobernadores del PRI. De inmediato logró distanciarse de los demás aspirantes, que ya no pudieron alcanzarlo. Esto le sirvió al PRI para evitar fricciones como en 2006, que llevaron a su candidato de ese año, Roberto Madrazo, al tercer sitio. Peña se movió muy anticipadamente y acaparó la atención como candidato único e inevitable. También en 2012, López Obrador logró ser el candidato del PRD, pero partió del tercer lugar. Aunque rebasó al segundo lugar y se acercó al ganador, terminó con mucha mayor distancia que en 2006, lo cual le dejó con menos fuerza dentro del PRD. Los contrapesos internos de las facciones del partido no le dejaron el margen de maniobra y la autoridad que tenía y que requería para garantizar su tercera candidatura en 2018. Por tanto, decidió abandonar el partido y formar el suyo propio, el Movimiento de Regeneración Nacional (Morena), amparado en el supuesto - correcto - de que buena parte del voto en los comicios presidenciales de 2006 y 2012 había sido más suyo que del PRD. El nuevo partido nació esencialmente personalista, por lo que no era posible oponerse o modificar las resoluciones del líder máximo. Así, la tercera 
candidatura de López Obrador en 2018 quedaba garantizada, lo que no hubiera sido seguro en el PRD. Al llevarse sus fichas, López Obrador abrió un boquete en el PRD (tal como el PRD lo había hecho con el PRI), para que se fueran los perredistas que no encontraran ya acomodo o que calcularan que Morena tenía mejor futuro que el PRD). La apuesta de López Obrador era que Morena sustituyera al PRD como eje de la izquierda mexicana, como ha ocurrido gradualmente desde entonces.

En las elecciones de 2018, López Obrador no solo llevaba la ventaja de haber estado en campaña continua desde 2000, sino que formalmente también se adelantó a los candidatos de otros partidos. Como, por definición, en Morena no había alternativas a la candidatura de López Obrador, nada impedía que se presentara muy anticipadamente, aunque los formalismos del registro oficial se llevaran a cabo mucho después. Además, en 2015 decidió autonombrarse presidente de su partido, cargo que no había ocupado (el primer presidente fue Martí Batres). Así, bajo la cobertura de esa posición pudo figurar en la publicidad asignada legalmente por el Instituto Nacional Electoral a su partido. En efecto, para impulsar su imagen como candidato presidencial nada mejor que ocupar formalmente la presidencia del partido. De esa manera pudo esquivar mejor las denuncias de realizar actos anticipados de campaña (lo cual está prohibido por la ley en términos genéricos, aunque la aplicación es imprecisa) y usar en su provecho la publicidad que le correspondía a su partido.

Un aspirante del PAN a la candidatura presidencial, Ricardo Anaya, que entonces era también presidente del partido, utilizó el mismo recurso para cerrar distancia respecto de la otra aspirante, Margarita Zavala, muy aventajada en las encuestas y que en 2016 aparecía en empate técnico con López Obrador. Hasta antes de la campaña, López Obrador apareció en 3.5 millones de promocionales de radio y televisión. Entre tanto, el PAN se fracturó en 2017, cuando Zavala declaró que se le habían cerrado las puertas para una contienda equitativa por la candidatura de su partido. Anaya logró manejar los hilos para ser candidato único de la coalición Con México al Frente, formada por el PAN, el PRD y el MC. Ese mismo año, José Antonio Meade, candidato del PRI, se alió con el PANAL y el PVEM. 
Para entonces, Anaya y Meade tenían ya poco tiempo para darse a conocer y difundir sus propuestas. Les quedaban seis meses para posicionarse, en contraste con los dos años y medio que López Obrador había promovido su candidatura. Antes de ser designados candidatos, analistas y encuestadores habían insistido en que las tendencias podían modificarse radicalmente una vez que se decidiera su candidatura. Sin embargo, a tres meses de despejar la incógnita, López Obrador seguía en la punta de las encuestas, incluso con mayor ventaja que antes. ${ }^{9}$

\section{Los candidatos del PRI y el PAN}

La forma de elegirlos y el perfil de los candidatos del PRI y el PAN explican también el triunfo de López Obrador. José Antonio Meade no era militante priista, pero se pensó que era una mejor opción para captar el voto de ciudadanos no priistas e incluso panistas, en virtud de que había cumplido funciones en el gobierno de Felipe Calderón. Sin embargo, su falta de militancia y su perfil técnico no convencieron a buena parte de los priistas de las bases, aunque las cúpulas se disciplinaran y cumplieran con la tradición del cierre simbólico de filas. El triunfo de Luis Videgaray (secretario de Hacienda y después de Relaciones Exteriores) al designar a su favorito como candidato priista, dejó fuertes fisuras internas con otros aspirantes (como Miguel Ángel Osorio Chong, secretario de Gobernación) y otras bases priistas, por más que ritualmente hubieran expresado su apoyo a Meade. La priista Claudia Ruiz Massieu dijo luego en una entrevista: "José Antonio Meade era un candidato de lujo, pero el [partido] no lo hizo suyo". ${ }^{10}$ En plena campaña hubo que cambiar al presidente del partido, el tecnócrata Enrique Ochoa, por René Juárez, que tenía una trayectoria política muy amplia en el partido y estaba más vinculado a las bases priistas. Con todo, llegó tarde, si bien el desprestigio del PRI (y la baja popularidad del presidente Peña Nieto) hacían una misión prácticamente imposible remontar el tercer sitio en que había iniciado Meade su campaña

${ }^{9}$ Cfr. Oraculus, marzo de 2018.

${ }^{10}$ La Jornada, 31 de julio de 2018. 
Es cierto que Meade tenía la ventaja de su vasta experiencia administrativa y gubernamental, y no se le conocía ningún enriquecimiento ilícito. Pero como parte de un gobierno priista (y otro panista) durante la campaña fue acusado de omisión y complicidad en actos de corrupción gubernamental (hubo muchos casos durante el gobierno de Peña Nieto). Meade cargó el fardo de las siglas priistas ante el enojo y el hartazgo de al menos $80 \%$ de la población. Su principal valor estaba en haber colaborado en un gobierno panista y no ser militante del PRI, pues podría atraer votos externos de quienes vieran en él una opción frente a Ricardo Anaya y Andrés López Obrador.

Por su parte, Ricardo Anaya logró consolidar el Frente por México junto con el PRD y MC, pese al vendaval que soplaba en su contra. Tenía una imagen juvenil y fresca que podría ser atractiva para millones de jóvenes que votarían por primera vez. Manejaba además una retórica ágil y firme que lució en los debates presidenciales. Pero la forma en que se apoderó de la candidatura de su partido jugó en su contra. Hizo pactos con dirigentes y después no los cumplió, y al provocar la salida de Margarita Zavala del partido se ganó la animadversión del influyente grupo calderonista dentro del PAN. No era un buen comienzo para aspirar

138 al triunfo en las elecciones. Fuera de su partido, proyectaba la imagen de un joven ambicioso capaz de fracturar al PAN con tal de ganar la candidatura. Todos los aspirantes que renunciaron a la contienda interna apelaron a la inequidad de la competencia.

Originalmente, el Frente por México convocó al sector de electores que no querían que repitiera el PRI en el gobierno pero tampoco que ganara López Obrador. Solo que no otorgaron su voto a Anaya, por la desconfianza que había generado. Por otra parte, no tenía gran experiencia de gobierno (fue subsecretario de Turismo en el régimen de Calderón) y el hartazgo ciudadano no solo se limitaba al PRI, sino que alcanzaba también al PAN por el gran fiasco que resultaron sus dos gobiernos. Anaya tuvo la libertad para deslindarse de Fox y de Calderón, pero eso no garantizaba que el PAN fuera a hacer lo que dijo que haría y no hizo de 2000 a 2012. 


\section{La ruptura entre el PRI y el PAN}

Se da por sentado que en 2006 y en 2012 se produjo un acuerdo entre las cúpulas del PRI y el PAN que ayudó a ganar, primero, a Felipe Calderón, y luego, a Enrique Peña Nieto. Se señala la alianza histórica, que López Obrador sintetiza como PRIAN, y que viene desde tiempos del presidente Salinas de Gortari (1988-1994), con las entonces llamadas "concertacesiones", en las que el PAN apoyaba al gobierno federal en asuntos económicos y federales a cambio del reconocimiento de triunfos en elecciones estatales. Desde luego, la coincidencia ideológica del PAN con la del neoliberalismo adoptado por el presidente Miguel de la Madrid (1982-1988) y Salinas de Gortari fue el eje del acuerdo. Se trataba de detener a la izquierda para garantizar la continuidad del modelo económico. Por tanto, cabía rivalizar en ciertos niveles (elecciones estatales o intermedias), y por un tiempo en las campañas presidenciales, pero una vez que quedara claro quién llevaba la delantera, había que cerrar filas en torno a quien pudiera derrotar a la izquierda contraria al neoliberalismo.

Ahora bien, en 2018 hubo una diferencia respecto de 1988, una confrontación entre el PRI y el PAN que podría obstaculizar el acuerdo partidario para enfrentar a la izquierda. La relación entre los partidos había sido cordial durante el gobierno de Peña Nieto (aunque no en los comicios estatales), pero se cortó abruptamente a raíz de las elecciones en Coahuila, El PAN no reconoció el triunfo priista, en parte porque la Procuraduría General de la República (PGR) se enfrentó a la candidata panista, lo que provocó un desencuentro entre ambos partidos que llevó al PRI a retener de manera dudosa la gubernatura de Coahuila, que según el PAN había ganado pero le fue arrebatada con trampas. El PRI no quiso ceder ni aceptó la anulación de las elecciones que permitía el Instituto Nacional Electoral. El Tribunal Electoral del Poder Judicial de la Federación (con mayoría priista) convalidó el triunfo del PRI.

A continuación, Ricardo Anaya arremetió para impedir el nombramiento del procurador Raúl Cervantes, cercano a Peña Nieto, como nuevo fiscal general. El gobierno filtró a los medios de comunicación 
una denuncia de lavado de dinero contra Anaya y su familia política, que dañó su imagen y lo frenó en las encuestas. La acusación resurgió más tarde en la PGR, que difundió datos sobre la investigación para dañar la imagen del candidato, pero en la medida en que le quedó claro a la opinión pública que hubo un uso electoral de la PGR, también se perjudicó al candidato del PRI. La sospecha de corrupción de Anaya quedó sembrada en buena parte del electorado, pero en las encuestas permaneció en segundo lugar, arriba de Meade, que no creció.

Anaya dijo que investigaría hasta sus últimas consecuencias al gobierno saliente, incluido al propio presidente Peña Nieto. La confrontación lastimó a los dos partidos en beneficio de López Obrador, que fue sumando los votos de estos descontentos.

Resultó imposible un nuevo pacto entre PRI y PAN, por las ofensas y agravios mutuos. Los obradoristas consideraban que prevalecerían los fuertes intereses de estos grupos y que la amenaza de un probable triunfo de López Obrador llevaría a que se dejaran de lado sus disputas y estrecharan sus manos. Pero el desacuerdo era irreversible. Circuló incluso la versión de que un grupo de grandes empresarios pidió al presidente Peña que apoyara a Anaya, incluso con una declinación formal de Meade, como única posibilidad para derrotar al candidato de Morena,

140 pero el presidente se habría negado. ${ }^{11}$

La última vez que se dio una confrontación semejante entre PRI y PAN fue en los años previos a 1988, cuando el gobierno de Miguel de la Madrid impidió en 1986 el triunfo del PAN en Chihuahua y Durango. Luego, en 1987 se desgajó del PRI la Corriente Democrática, con su candidato a la presidencia Cuauhtémoc Cárdenas, que le complicó el escenario al PRI y le impuso graves costos de credibilidad y legitimidad. En cambio, en 1994 al PAN ya se le habían reconocido algunas gubernaturas, por lo que pudo ir en buenos términos con el PRI a las elecciones presidenciales de ese año, y avaló de inmediato el triunfo del candidato priista, Ernesto Zedillo. En 2000, la alternancia encontró un ambiente político calmado y civilizado. Zedillo reconoció triunfos locales de las dos principales fuerzas opositoras y favoreció una reforma electoral que dio paso a una plena de 2018

${ }^{11}$ Salvador García Soto, "Los mensajeros entre Peña y Amlo", El Universal, 5 de julio 
competitividad entre partidos. ${ }^{12}$ En 2006, frente al desafío de López Obrador, de último momento el PRI (por medio de varios de sus gobernadores) y el PAN llegaron a un acuerdo para que los priistas reconocieran el cerrado triunfo de Felipe Calderón. ${ }^{13}$ Todavía en 2012 hubo un nuevo acuerdo para facilitar la campaña y el reconocimiento del triunfo del priista Enrique Peña Nieto. Pero la confrontación entre PRI y PAN por las elecciones de 2017 radicalizó al segundo y propició la consecuente ruptura de hostilidades políticas entre ambos partidos. Afines de marzo de 2018, el promedio de las encuestas marcaba un ligero descenso tanto de Meade como de Anaya, y un avance de López Obrador, que sumaba $40 \%$ (sin incluir a los indecisos) frente a $28 \%$ de Anaya y $22 \%$ de Meade. ${ }^{14}$ Esa distancia se fue abriendo conforme el golpeteo entre PRI y PAN se prolongó e intensificó a lo largo de las campañas. Nunca hubo una tregua, y menos un arreglo entre ambos partidos, que de cualquier manera ya hubiera sido tardío.

\section{Transferencia del voto útil}

El voto estratégico o útil se define como aquel que se emite a favor de un partido en los comicios legislativos, pero no por el candidato presidencial de ese mismo partido. Ocurre cuando el candidato propio no es uno de los dos punteros, de modo que un voto por él se desperdicia y el votante decide entregarlo al que le parece el menos malo de los punteros. $\mathrm{O}$ bien cuando un militante o votante duro de un partido no se identifica con su propio candidato y prefiere votar por otro, aunque de todos modos vota por su partido en las elecciones legislativas.

Por tanto, en el primer semestre de 2018 se podía suponer que un buen número de votantes y militantes del PRI o sus aliados (PANAL y PVEM) iban a dar su voto presidencial a un candidato diferente de Meade. Y lo mismo se pensaba respecto de los votantes del PAN o sus aliados (PRD

${ }^{12}$ José Antonio Crespo, Jaque al rey, 1996, México, Planeta.

${ }^{13}$ José Antonio Crespo, 2006: hablan las actas. Las debilidades de la autoridad electoral, 2008, México, Random House Mondadori.

${ }^{14}$ Oráculus, Promedio de encuestas, 31 de marzo de 2018. 
y $\mathrm{MC})$. En el primer caso, en parte porque los votantes entenderían que Meade no pasaría del tercer sitio, y en parte porque no se identificaban con el perfil del candidato (sin militancia en el PRI, técnico del neoliberalismo y miembro del primer círculo de Peña Nieto). En cuanto a Anaya, algunos panistas habrían podido desertar por el conflicto interno, mientras que perredistas y votantes del MC podrían identificarse más con otro candidato y no con un panista, pese a entregar el voto legislativo a su partido. Y si bien hubo una disputa entre el PRI y el PAN para atraer el voto de su adversario (como extensión de la confrontación entre ambos partidos), el más probable beneficiario del voto útil iba a ser López Obrador, en virtud de cómo se había comportado ese voto en 2006 y en 2012. En esas elecciones, muchos electores que sufragaron por diputados de partidos distintos a la coalición obradorista (o por ninguno, anulando su voto), lo hicieron por López Obrador en las presidenciales. En 2006 el voto útil sumó más de cuatro millones y en 2012, más de dos millones y medio. Casi todos estos votos fueron a dar a las arcas de López Obrador. Los datos precisos son los siguientes:

\section{CUADRO 1}

Voto útil en 2006

Partidos y segmentos que aportaron el voto útil

\begin{tabular}{lcccc}
\hline & PRI-PVEM & PANAL & Casillas especiales & Total \\
\hline Presidente & 9301441 & 401804 & 41791322 & \\
Diputados & 11619679 & 1872283 & 41195198 & \\
Voto útil & 2318238 & 1470470 & 596124 & 4384841 \\
Porcentaje & $53 \%$ & $33 \%$ & $14 \%$ & $100 \%$ \\
\hline
\end{tabular}

Partidos y segmentos receptores del voto útil

\begin{tabular}{lccccc}
\hline & PAN & PRD-PT-MC & PASC & Nulos & Total \\
\hline Presidente & 15000284 & 14756350 & 1128850 & 1202593 & \\
Diputados & 13753633 & 11941842 & 845749 & 1162012 & \\
Voto útil & 1246651 & 2814508 & 283101 & 40581 & 4384841 \\
Porcentaje & $28 \%$ & $5 \%$ & $6 \%$ & $1 \%$ & $100 \%$ \\
\hline
\end{tabular}

Fuente: Instituto Nacional Electoral. 
Debe destacarse en primer lugar que la proporción del voto útil en 2006 fue mucho mayor que en las anteriores elecciones: casi 4400000 (10.5\% del total), más del doble que en las elecciones del $2000(4.5 \%)$ y tres veces más que en 1994 (3\%). La interpretación es que priistas y panalistas tuvieron una mayor disposición a emitir un voto útil que los perredistas seis años antes (en 2000). ¿Quiénes fueron los principales receptores de ese voluminoso voto útil? Se pensaría que el PAN, dada la alianza de gobernadores del PRI con el PAN por medio de Elba Esther Gordillo, dirigente del PANAL. Muchos analistas incluso explicaron el estrecho triunfo de Calderón por el voto útil proveniente del PANAL e incluso del PRI. Sin embargo, al contrario de esta tesis, el voto útil proveniente del PRI y el PANAL favoreció principalmente a López Obrador. La coalición de este candidato recibió $65 \%$ del voto útil combinado del PRI, PANAL y los abstencionistas parciales (dos terceras partes). Mientras tanto, Felipe Calderón del PAN recibió solo $28 \%$ de ese voto útil, menos de la mitad. Curiosamente, un tercer partido recibió también una parte del voto estratégico pese a no tener posibilidad alguna de triunfo: el Partido Alternativa Social-Demócrata y Campesina (PASC) con Patricia Mercado como su candidata (quien recibió $6 \%$ de ese voto útil). Se asume que la intención era favorecer el registro de un partido que representaría una ideología poco expresada en México, la socialdemocracia (que ni el PRI, ni el PAN ni el PRD representaban).

En 2012, los receptores del voto útil fueron exclusivamente López Obrador (PRD) y el candidato priista Enrique Peña Nieto. Y quienes aportaron ese voto fueron el PAN (aunque en pequeña medida), el PANAL y, sobre todo, el segmento de electores que decidieron destruir o anular su voto por los candidatos a diputados pero sí votaron por presidente.

CUADRO 2

Voto útil en 2012

Partidos y segmentos que aportaron el voto útil

\begin{tabular}{lccccc}
\hline & $P A N$ & PANAL & Anulistas & Abstencionistas & Total \\
\hline Presidente & 12732630 & 1146085 & 1257481 & 50143616 & \\
Diputados & 12885414 & 2031537 & 2506527 & 49775933 & \\
Voto útil & 152784 & 885452 & 1249046 & 367683 & 2654964 \\
Porcentaje & $6 \%$ & $33 \%$ & $47 \%$ & $14 \%$ & $100 \%$ \\
\hline
\end{tabular}


Partidos receptores del voto útil

\begin{tabular}{lccc}
\hline & PRI-VERDE & PRD & Total \\
\hline Presidente & 19158592 & 15848827 & \\
Diputados & 18938363 & 13414143 & \\
Voto útil & 220229 & 2434684 & 2654913 \\
Porcentaje & $8 \%$ & $92 \%$ & $100 \%$ \\
\hline
\end{tabular}

Fuente: Instituto Nacional Electoral.

En las elecciones de 2012, el voto útil cayó a 5\% de la votación total (el mismo que en 2000 y la mitad que en 2006). Una explicación posible es que los priistas, cuando su candidato ha perdido la posibilidad de ganar, están más dispuestos a emitir un voto útil. Así pasó con Roberto Madrazo en 2006, que quedó en tercer lugar (con 22\% de la votación). Pero como en 2012 nunca estuvieron abajo en las encuestas, se mantuvieron fieles con su candidato (Peña Nieto). En cifras totales, el voto útil en 2012 sumó 2654913 (casi la mitad de los 4384841 votos útiles de 2006). ¿A quién benefició ese voto en 2012 ? En muy poca proporción, al candidato del PRI, que recibió solo $8 \%$ del total (casi todo, probablemente, de panistas). En cambio, López Obrador captó el restante 92\%, una proporción mayor que en 2006 (aunque cuantitativamente fueron menos votos). Se puede inferir que la mayoría de los electores del PANAL, los anulistas y quienes votaron en casillas especiales se inclinaron por López Obrador, de seguro con la intención de impedir el retorno del PRI al poder (o en el caso de los panalistas, por una identificación real con el candidato del PRD, como ocurrió en buena medida también en 2006 con ese partido y con los priistas). En efecto, aun suponiendo que la totalidad del voto útil recibido por el PRI (más de 220 000) hubiera provenido del PANAL (lo que implicaría que los panistas que dieron un voto útil lo habrían hecho por López Obrador, cosa poco probable en ese momento), de cualquier forma el PANAL habría aportado el doble de esos votos, más de 665000 , al candidato perredista. Sin embargo, es más probable que el grueso del voto útil de los panistas haya ido a dar a Peña Nieto, por lo que es razonable pensar que el voto útil del PANAL entregado a López Obrador fue abrumador. No es ilógico suponer que 
los maestros se identificaran más con la izquierda que con el PAN (pese a la cercanía de su dirigente, la Maestra Gordillo, con tal partido). En ese 2012, el PAN fue donante de voto útil al haber caído al tercer sitio, sin posibilidad de triunfo. Sin embargo, ese voto útil fue muy reducido: 153000 votos, lo que significó solo 6\% del total. La mayoría de electores panistas dieron un voto de lealtad a su candidata. También es probable que el escaso voto útil panista se haya dirigido al candidato del PRI, dado que López Obrador les genera una aversión mayor que el propio PRI. El PANAL, en cambio, aportó una gran proporción de voto útil $(33 \%)$.

En 2012 se registró un fenómeno notable: el conjunto de electores apartidistas, que comprende a los abstencionistas parciales (votan solo para presidente en casillas especiales por hallarse fuera de su circunscripción) o quienes anulan su voto legislativo pero votan por presidente, aportaron el $61 \%$ del voto útil, lo que no había ocurrido en elecciones anteriores. ¿Qué explicación se daba a este fenómeno? Probablemente fue en parte repercusión del movimiento anulista de 2009, cuando muchos electores contemplaron la opción de anular su voto como protesta en lugar de abstenerse o sufragar por algún partido. ${ }^{15}$ En cambio, en 2012 muchos de los que anularon su voto por legisladores optaron por participar en las presidenciales. Entre los votos para diputados se registraron $5 \%$ nulos, pero para presidente el voto anulado fue de solo $2.5 \%$. Y la gran mayoría de esos votantes favoreció a López Obrador.

Dadas las cifras de 2006 y 2012, podía esperarse que en 2018 el voto útil favoreciera también a López Obrador. El hecho de que el candidato priista quedara en tercer sitio impulsaría a muchos electores del PRI, el PANAL y el PVEM a preferir el voto útil. Y dada la ideología nacionalista revolucionaria tanto de las bases priistas y los maestros del PANAL, era más probable que se inclinaran a favor de López Obrador que de un panista (Anaya o cualquier otro). Y en el caso de los votantes del PRD y MC, también era más probable que se decantaran por alguien de su propia ideología (López Obrador) y no por un candidato panista o uno

${ }^{15}$ Cfr. José Antonio Crespo, "México 2009; abstención, voto nulo y triunfo del PRI”, 2010, Cuadernos del CIDE, núm. 220. 
priista y neoliberal. En cuanto a los panistas, si bien los priistas esperaban que pudieran votar por Meade (dado que no era militante del PRI y había formado parte del gobierno de Calderón), era más probable que mantuvieran un voto fiel a su candidato, como ocurrió también en 2012. ${ }^{16}$ Y en efecto, así ocurrió. El PRI, el PVEM y el PANAL aportaron casi el $50 \%$ de todo el voto útil (más de ocho millones de votos): el Frente aportó $35 \%$ de ese voto y el restante $15 \%$ provino de votantes que anularon en las legislativas pero no en las presidenciales o que lo hicieron por candidatos independientes para diputados, más los votos en casillas especiales, que son únicamente para presidente.

CUADRO 3

Distribución del voto útil (2018)

Partidos que aportaron voto útil

\begin{tabular}{lcccc}
\hline & & \multicolumn{3}{c}{ Nulos, independientes, } \\
casillas especiales & Total \\
\hline Presidente & 12610120 & 9289853 & 1923876 & \\
Diputados & 15549755 & 13397304 & 3135701 & \\
Voto útil & 3098671 & 4107451 & 1211825 & 8417947 \\
Porcentaje & $37 \%$ & $49 \%$ & $4 \%$ & $100 \%$ \\
\hline
\end{tabular}

Partidos y segmentos que recibieron el voto útil

\begin{tabular}{lccc}
\hline & MORENA, PT, PES & $\begin{array}{c}\text { Jaime Rodriguez } \\
\text { (el Bronco) }\end{array}$ & Total \\
\hline Presidente & 30086483 & 2961732 & \\
Diputados & 24538267 & & \\
Voto útil & 5548216 & 2961732 & 8509948 \\
Porcentaje & $65 \%$ & $35 \%$ & $100 \%$ \\
\hline
\end{tabular}

Fuente: Instituto Nacional Electoral, Programa de Resultados Electorales Preliminares.

¿Cómo se comportaron los votantes del Frente por México? Según lo esperado. Cuando en 2012 el PAN ya no fue competitivo, sus votantes sufragaron pese a todo por su candidata; solo $1 \%$ del elector panista dio un voto útil (presumiblemente a favor de Peña Nieto). Sin embargo, en

${ }^{16}$ Crespo, 2018: ¿Amlo presidente? 
las elecciones del Estado de México se percibió que panistas votaron por Morena y el PRD (ambos ganadores en las zonas de tradicional voto panista), por lo que quizá muchos votarían esa vez por López Obrador. Sin embargo, su comportamiento fue semejante al de 2012, pues fueron fieles a Anaya y solo 1\% sufragó por un candidato distinto (haya sido el Bronco o López Obrador). En cambio, era absolutamente previsible que los votantes del PRD y MC votaran más por López Obrador que por Anaya y menos aún por Meade. En efecto, $46 \%$ de los perredistas dieron su voto útil, y en el caso del MC, el porcentaje llegó al 60\%. La coalición resultó un mal negocio para el PAN, pues abrió espacios a sus aliados en la contienda para diputados a cambio de muy pocos votos en la presidencial.

\section{La nueva y artificial mayoría legislativa}

Los resultados de las elecciones de 2018 no solo dieron un abrumador triunfo a López Obrador, con 53\% de la votación, sino que le brindaron una mayoría absoluta en ambas cámaras del Congreso, además de la posibilidad de conseguir la mayoría calificada de dos terceras partes de los escaños, necesaria para modificar la Constitución. Es una situación parecida a la que prevalecía con el PRI cuando aún era partido hegemónico. El PRI perdió la mayoría calificada de la Cámara Baja por primera vez en 1988. Entonces Carlos Salinas de Gortari habló de que terminaba la era de un partido "prácticamente único" (es decir, hegemónico). En 1993 se reformó la ley electoral para impedir que un partido pudiera reunir una mayoría calificada; cuando mucho, tendría $60 \%$ de las curules (y ya no el 66\% requerido). En 1997, Ernesto Zedillo perdió la mayoría absoluta en la Cámara de Diputados y, desde entonces, ningún presidente la ha logrado recuperar. En adelante, hubo que pactar coaliciones para acercarse o conseguir dicha mayoría absoluta, pero aun así no se contaba con la mayoría calificada. Zedillo no pudo realizar una reforma energética presentada en 1998, pues el PAN la rechazó. Más tarde, Vicente Fox intentó igualmente emprender una reforma energética y otra fiscal, por la que medicinas y alimentos se gravarían con 
el impuesto al valor agregado, y el PRI rechazó ambas iniciativas. Felipe Calderón quiso impulsar también una reforma energética, que fue obstruida nuevamente por el PRI. Pese a la afinidad ideológica entre el PRI neoliberal y el PAN (que dio lugar al membrete de PRIAN), en realidad el PRI decidió obstruir a los gobiernos panistas con vistas a que el electorado le devolviera el poder (como ocurrió en 2012). En 2012, Enrique Peña Nieto pudo convencer a las dirigencias de los partidos opositores (PAN y PRD) de respaldar una serie de reformas constitucionales pendientes, en tanto coincidieran con sus plataformas correspondientes, a través del llamado Pacto por México. Las cúpulas del PAN y el PRD decidieron sentarse a negociar con el gobierno y aprobar aquello que fuera compatible con su respectivo programa. Así se aprobaron reformas como la de comunicaciones, la educativa, la laboral y otra electoral. La reforma energética solo fue aprobada por el PRI y el PAN (pues iba contra el programa histórico del PRD), y la reforma fiscal solo fue aceptada por el PRI y el PRD (pues iba contra las convicciones del PAN). Las bases de los partidos acusaron a sus dirigencias de traicionar sus principios al sentarse a negociar con el gobierno de Peña Nieto, pese a que en realidad las reformas no iban contra las plataformas de los partidos firmantes.

Respecto de las elecciones de 2018, si bien López Obrador obtuvo $53 \%$ de los votos, los diputados y senadores de su coalición recibieron solamente $43 \%$. Ahora bien, dada la fórmula electoral vigente en México, los partidos mayoritarios pueden quedar sobrerrepresentados, esto es, que obtengan un porcentaje de curules superior al porcentaje de votos obtenidos en las urnas. En la Cámara de Diputados, los de mayoría relativa son 300 y los de representación proporcional (o plurinominales), 200. En otras democracias, la representación proporcional tiene la función de equiparar el porcentaje de votos con el porcentaje de escaños. Como señala Dieter Nolen: "La representación proporcional se da cuando la representación política refleja, lo más exactamente posible, la distribución de los votos entre los partidos [e] impide la constitución de mayorías parlamentarias demasiado artificiales que no corresponden a una mayoría real del electorado". ${ }^{17}$ En la medida en que no se dé esa correspon-

${ }^{17}$ Dieter Nolen, Sistemas electorales y partidos políticos, 1995, México, FCE, pp. 88 y 112. 
dencia entre votos y escaños, se distorsiona la representación de los electores en el Congreso.

Cuando en México se introdujeron los diputados de representación proporcional en 1979, no fue para equiparar el porcentaje de votos con el porcentaje de curules, como sucede en los países democráticos que tienen esa fórmula, sino solo para aminorar la sobrerrepresentación del PRI y la subrepresentación de la oposición. Se trataba de generar incentivos para que los partidos opositores pudieran prosperar y legitimar en cierta medida el sistema político y electoral vigente, pero sin que el PRI perdiera su hegemonía. La fórmula para distribuir los diputados de representación proporcional sufrió cambios y al cabo fue acotada en 1996. Sin embargo, solo se restringió la sobrerrepresentación, en lugar de eliminarla por completo. Con las nuevas modificaciones, ningún partido podría obtener una sobrerrepresentación mayor al $8 \%$ tras el reparto de diputados plurinominales, pero sí dentro de ese límite. Así, un partido que obtuviera poco más del $42 \%$ de la votación, podría aún alcanzar la mayoría absoluta, y en esa medida, los partidos minoritarios quedarían subrepresentados en esa misma proporción. Dicha disposición sobrevivió a varias otras reformas electorales. Los partidos opositores pusieron atención en otros temas de equidad, pero se olvidaron de cambiar la fórmula de reparto de diputados que todavía permite la sobrerrepresentación.

El partido más beneficiado fue el PRI, si bien el PAN también lo hizo en ciertos momentos. Ahora, en 2018 el gran favorecido fue el obradorismo, pues en la Cámara de Diputados su coalición quedó sobrerrepresentada casi $20 \%$ (y en esa proporción el resto de partidos quedaron subrepresentados). En efecto, Morena, el PES y el PT obtuvieron $43 \%$ de la votación para diputados (10\% menos que López Obrador en la presidencial), pero suman $62 \%$ de las curules. En otras palabras, $43 \%$ de los votantes quería darle a López Obrador una mayoría absoluta en la Cámara de Diputados, pero el restante $57 \%$ no votó por eso (incluido el 10\% de electores que votaron por López Obrador para presidente, pero no por su coalición para el legislativo). ¿Por qué consiguió esa coalición una gran mayoría? Por la sobrerrepresentación estipulada en la 
anacrónica fórmula de reparto de las curules de representación proporcional. Sin sobrerrepresentación, la coalición obradorista habría obtenido solo 215 diputados, pero tiene 306 (91 curules más de las que determinó el electorado). Al mismo tiempo, los partidos de oposición (incluido el PRI) quedan subrepresentados en la misma proporción. En particular, el PRI quedó sumamente subrepresentado, porque obtuvo $16 \%$ de la votación (que en principio le daría 80 diputados), pero tiene solamente 46, es decir, 9\% de las curules; una subrepresentación del 11\%. El PAN quedó menos subrepresentado; su votación fue de casi $18 \%$ y su bancada alcanza 79 diputados (16\%).

Por otro lado, si la ley establece que la sobrerrepresentación máxima por partido será del 8\%, ¿cómo es que la coalición obradorista está sobrerrepresentada en $18 \%$ ? Precisamente porque es una coalición de tres partidos, cada uno con derecho de hasta $8 \%$ de sobrerrepresentación. Así, en principio, la coalición podría tener hasta $24 \%$ de sobrerrepresentación. Por ejemplo, el PT obtuvo cerca del 4\% de la votación (equivalente a 20 curules) pero por su convenio de coalición con Morena alcanzó 61 escaños (12\%), es decir, tres veces más de lo que la ciudadanía decidió darle. Es 8\% de sobrerrepresentación. El PES, por su parte, no alcanzó el 3\% requerido por la ley para conservar el registro. Por tanto, no le tocaron diputados plurinominales, pero ganó en 55 distritos de mayoría (equivalentes a $11 \%$ de las curules) que retiene pese a haber perdido el registro. Lo que ocurrió fue que muchos de esos candidatos ganadores en realidad pertenecían a Morena, pero aparecieron bajo las siglas del PES en virtud de la coalición Juntos Haremos Historia (Morena, PT y PES). Morena por sí mismo captó 38\% de la votación, con un total de 191 diputados (38\%); es decir, no estaría sobrerrepresentado. Sin embargo, dado que 56 de los candidatos de sus aliados PT y PES en realidad eran de Morena, se integraron a la bancada de su verdadero partido, con lo cual de 191 diputados Morena pasó a obtener 247 escaños (49.5\% de las curules), es decir, casi 12\% más que la votación que obtuvo. No es ilegal, pero sí una forma de burlar el límite de sobrerrepresentación estipulado por la ley. Además, la bancada de Morena se incrementó con la incorporación de diputados de otros partidos, como el 
PVEM, que aportó cinco (mediante el acuerdo entre partidos), y el PRI, que aportó otros cuatro. Esto último suele ocurrir en otros países (si bien se toman medidas legales para dificultarlo), pero en México no es ilegal, por mucho que sea una maniobra que distorsiona la voluntad del electorado en las urnas. El jurista Elizur Arteaga escribió:

En las cámaras que integran el Congreso de la Unión es práctica común el prestarse o regalarse diputaciones o senadurías de un partido a otro con el fin de que una facción alcance mayoría absoluta. Hacerlo es inadmisible, va contra el fondo que explica un sistema democrático: los electores, entre ellos los que lo hicieron por el Verde Ecologista, votaron por un programa, por una ideología. Cuando, una vez electos, son transferidos para formar parte de la bancada de otro partido, o asumen el compromiso de votar en forma constante y sistemática por lo que propone otro partido, significa renunciar a la ideología partidista y abjurar un programa político. Y hacerlo, sin contar con la anuencia de sus electores, es traicionarlos. ${ }^{18}$

En total, Morena cuenta con 256 diputados (de los 191 originales), lo que representa $51 \%$, con $13 \%$ de sobrerrepresentación respecto de la votación que recibió en las urnas. La coalición obradorista concentrará 313 diputados, a 17 curules de alcanzar la mayoría calificada (las dos terceras partes que se exige para modificar la Constitución). En resumen, la mayoría está determinada, en parte, por el voto ciudadano, pero se acrecienta con las distorsiones de la ley electoral, que todavía incluye una disposición anacrónica para el reparto de las curules, resabio de la hegemonía priista que ahora permite el surgimiento de una nueva hegemonía legislativa en otra fuerza política de 2018 .

${ }^{18}$ Elizur Arteaga, “Así no se logrará la Cuarta Transformación”, Proceso, 10 de septiembre 
Se prohíbe su reproducción total o parcial por cualquier medio, incluido electrónico, sin permiso previo y por escrito de los editores. 